\title{
ONE-POT REGIOSELECTIVE SYNTHESIS OF NITROPHENYLOXAZOLINYL STYRENE OXIDES BY THE DARZENS REACTION OF VICARIOUS NUCLEOPHILIC SUBSTITUTION-FORMED CARBANIONS OF 2-DICHLOROMETHYL-4,4- DIMETHYLOXAZOLINE
}

\author{
Saverio Florio, ${ }^{\mathrm{a}^{*}}$ Patrizia Lorusso, ${ }^{\mathrm{b}}$ Catia Granito, ${ }^{\mathrm{b}}$ Renzo Luisi ${ }^{\mathrm{a}}$ and Luigino Troisi ${ }^{\mathrm{b}^{*}}$ \\ ${ }^{a}$ Dipartimento Farmaco-Chimico, University of Bari, Via E. Orabona 4, I-70126-Bari, Italy \\ C.N.R., Istituto di Chimica dei Composti Organometallici "ICCOM", Sezione di Bari, \\ ${ }^{b}$ Dipartimento di Scienze e Tecnologie Biologiche ed Ambientali, University of Lecce, \\ Via Pro.le Lecce-Monteroni, 73100 Lecce, Italy
}

\section{Supporting Information}

List of the Content

- General procedures S1

- ${ }^{1} \mathrm{H}$ and ${ }^{13} \mathrm{C}$ NMR of Oxazolinyloxiranes 8a-e

S4

- ${ }^{1} \mathrm{H}$ and ${ }^{13} \mathrm{C}$ NMR Nitrobenzyloxazoline $\mathbf{1 0}$

S9

- ${ }^{1} \mathrm{H}$ and ${ }^{13} \mathrm{C}$ NMR of Oxazolinyloxiranes 11a-f

S10

- ORTEP view of Oxazolinyloxiranes 8a and 11c

S16 
General. The ${ }^{1} \mathrm{H}$ and ${ }^{13} \mathrm{C}$ NMR spectra were recorded on a $400 \mathrm{MHz}$ apparatus (400 MHz and 100 $\mathrm{MHz}$, for ${ }^{1} \mathrm{H}$ and ${ }^{13} \mathrm{C}$, respectively), with $\mathrm{CDCl}_{3}$ as solvent and TMS as internal standard $(\delta=7.24$ for ${ }^{1} \mathrm{H}$ spectra; $\delta=77.0$ for ${ }^{13} \mathrm{C}$ spectra). GC-MS analyses were performed on gas chromatograph equipped with 5\% diphenyl/ 95\% dimethylpolysiloxane capillary column, 30 m, $0.25 \mathrm{~mm}$ i.d., with a mass-selective detector operating at $70 \mathrm{eV}$ (EI). Melting points were determined on an electrothermal melting point apparatus and were uncorrected. X-ray analysis was performed on Bruker-Nonius KappaCCD. TLC were performed on silica gel plates with F-254 indicator; viewing was by UV light $(254 \mathrm{~nm})$. Column chromatographies were performed on silica gel $(63-200 \mu \mathrm{m})$, with petroleum ether/ethyl acetate (AcOEt) mixtures as eluents. All reactions involving air-sensitive reagents were performed under nitrogen in oven-dried glassware using syringe/septum cap techniques. DMF and DMSO were distilled and stored on molecular sieves ( $5 \AA$ ) prior to use. Starting materials were commercially available or were prepared by known methods; in particular, 2-dichloromethyl-4,4-dimethyl-4,5-dihydro-oxazole 2 was prepared by chlorination (2 eq. of tertbutylhypochlorite) of commercially available 2,4,4-trimethyl-4,5-dihydrooxazole 1 following the reported synthetic protocol for the monochlorination. ${ }^{1}$

General procedure for the preparation of $p$-nitrophenyloxazolinyloxiranes $(8 \mathbf{a}-\mathbf{e})$. A solution of $2(1 \mathrm{mmol})$ and nitrobenzene $(1.1 \mathrm{mmol})$ in $2 \mathrm{~mL}$ of DMF was added dropwise, under $\mathrm{N}_{2}$, to a vigorously stirred suspension of powdered $t$-BuOK $(3 \mathrm{mmol})$ in $8 \mathrm{~mL}$ of DMF at $-50^{\circ} \mathrm{C}$. Then, a solution of aldehyde $(2 \mathrm{mmol})$ in $1 \mathrm{~mL}$ of DMF was immediately added. The reaction was kept at $50^{\circ} \mathrm{C}$ for $1 \mathrm{~h}$, then allowed to warm up to room temperature. After $12 \mathrm{~h}$, the mixture was poured into water $(100 \mathrm{ml})$ and extracted with dichloromethane $(3 \times 20 \mathrm{~mL})$. The combined organic layers were washed with distilled water $(2 \times 50 \mathrm{~mL})$, dried $\left(\mathrm{Na}_{2} \mathrm{SO}_{4}\right)$ and concentrated in vacuo to give the $p$ nitrophenyl-oxazolinyl-oxiranes 8a-e ( yields: 37-87\%) which can be further purified by column chromatography (silica gel; petroleum ether/AcOEt, 1:1).

\footnotetext{
${ }^{1}$ (a) Breton, P.; André-Barrès, C.; Langlois, Y.; Synth. Comm. 1992, 22, 2543. (b) Mintz, M. J.; Walling, C. Organic Syntheses Collect. Vol. V, Wiley \& Sons: New York, 1973, 184.
} 


\section{General procedure for the preparation of o-nitrophenyloxazolinyloxiranes (11a-f). A}

solution of $2(1 \mathrm{mmol})$ and nitrobenzene $(1.1 \mathrm{mmol})$ in $2 \mathrm{~mL}$ of THF was added dropwise, under $\mathrm{N}_{2}$, to a vigorously stirred suspension of powdered $t$-BuOK $(3 \mathrm{mmol})$ in $8 \mathrm{~mL}$ of THF at $-80^{\circ} \mathrm{C}$. Then, a solution of aldehyde $(2 \mathrm{mmol})$ in $1 \mathrm{~mL}$ of THF was immediately added. The reaction was kept at $-80^{\circ} \mathrm{C}$ for $1 \mathrm{~h}$, then allowed to warm up to room temperature. After $2.5 \mathrm{~h}$, the mixture was poured into distilled water $(100 \mathrm{ml})$ and extracted with dichloromethane $(3 \times 20 \mathrm{~mL})$. The combined organic layers were dried $\left(\mathrm{Na}_{2} \mathrm{SO}_{4}\right)$ and concentrated in vacuo to give the $o$ nitrophenyloxazolinyloxiranes 11a-f (yields: 61-95\%) which can be further purified by column chromatography (silica gel; petroleum ether/AcOEt, 1:1).

Preparation of bisoxazolinylethene 7: A solution of 2 (1 mmol) and nitrobenzene $(1.1 \mathrm{mmol})$ in 2 $\mathrm{mL}$ of DMF was added dropwise, under $\mathrm{N}_{2}$, to a stirred suspension of $\mathrm{t}-\mathrm{BuOK}(3 \mathrm{mmol})$ in $8 \mathrm{~mL}$ of $\mathrm{DMF}$ at $-50^{\circ} \mathrm{C}$. The reaction was kept at $-50^{\circ} \mathrm{C}$ for $1 \mathrm{~h}$, then allowed to warm up to room temperature. After $24 \mathrm{~h}$ the mixture was poured into water $(100 \mathrm{ml})$ and extracted with dichloromethane $(3 \times 20 \mathrm{~mL})$. The combined organic layers were washed with distilled water $(2 \times$ $50 \mathrm{~mL})$, dried $\left(\mathrm{Na}_{2} \mathrm{SO}_{4}\right)$ and concentrated in vacuo to give a crude that was purified by flash chromatography (Petroleum ether/Ethylacetate : 1/1). Two fraction were collected with $R_{f}: 0.55$ and 0.3 , corresponding to the $Z$ and $E$ alkene 7 respectively.

General procedure for the preparation of nitrobenzyloxazoline 5, 6 and 10: A solution of 2 (1 mmol) and nitrobenzene $(1.1 \mathrm{mmol}$ ) in $2 \mathrm{~mL}$ of DMF (or THF for the ortho isomer) was added dropwise, under $\mathrm{N}_{2}$, to a stirred suspension of t-BuOK (3 mmol) in $8 \mathrm{~mL}$ of DMF (or THF) at $50^{\circ} \mathrm{C}\left(-80{ }^{\circ} \mathrm{C}\right.$ for the reaction in THF). The resulting dark red solution was stirred at that temperature for $1.5 \mathrm{~h}$ before quenching with a solution of $\mathrm{NH}_{4} \mathrm{Cl}$. The resulting mixture was extracted with AcOEt $(2 \times 50 \mathrm{~mL})$, dried $\left(\mathrm{Na}_{2} \mathrm{SO}_{4}\right)$ and concentrated in vacuo and the crude purified by flash chromatography. 

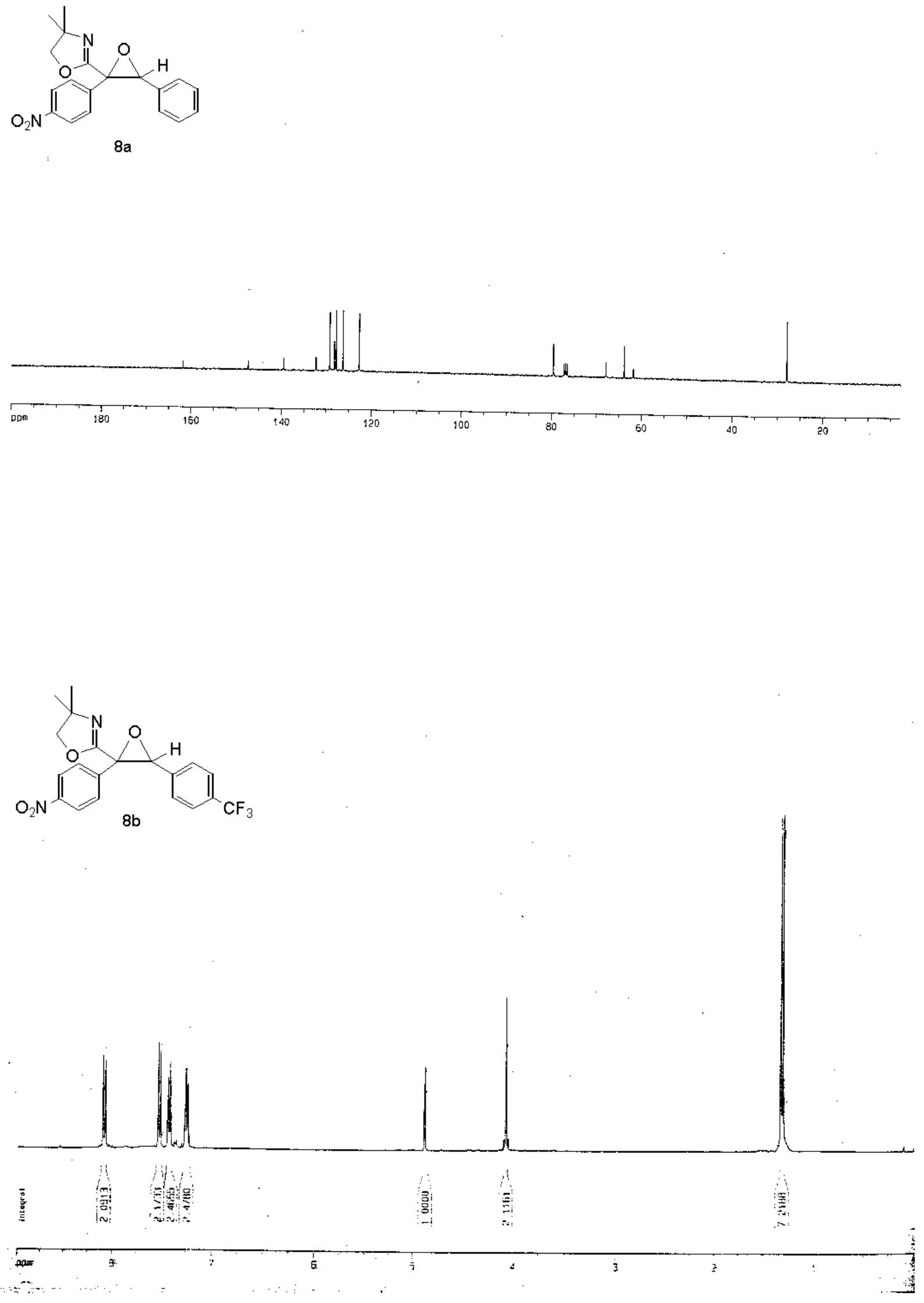

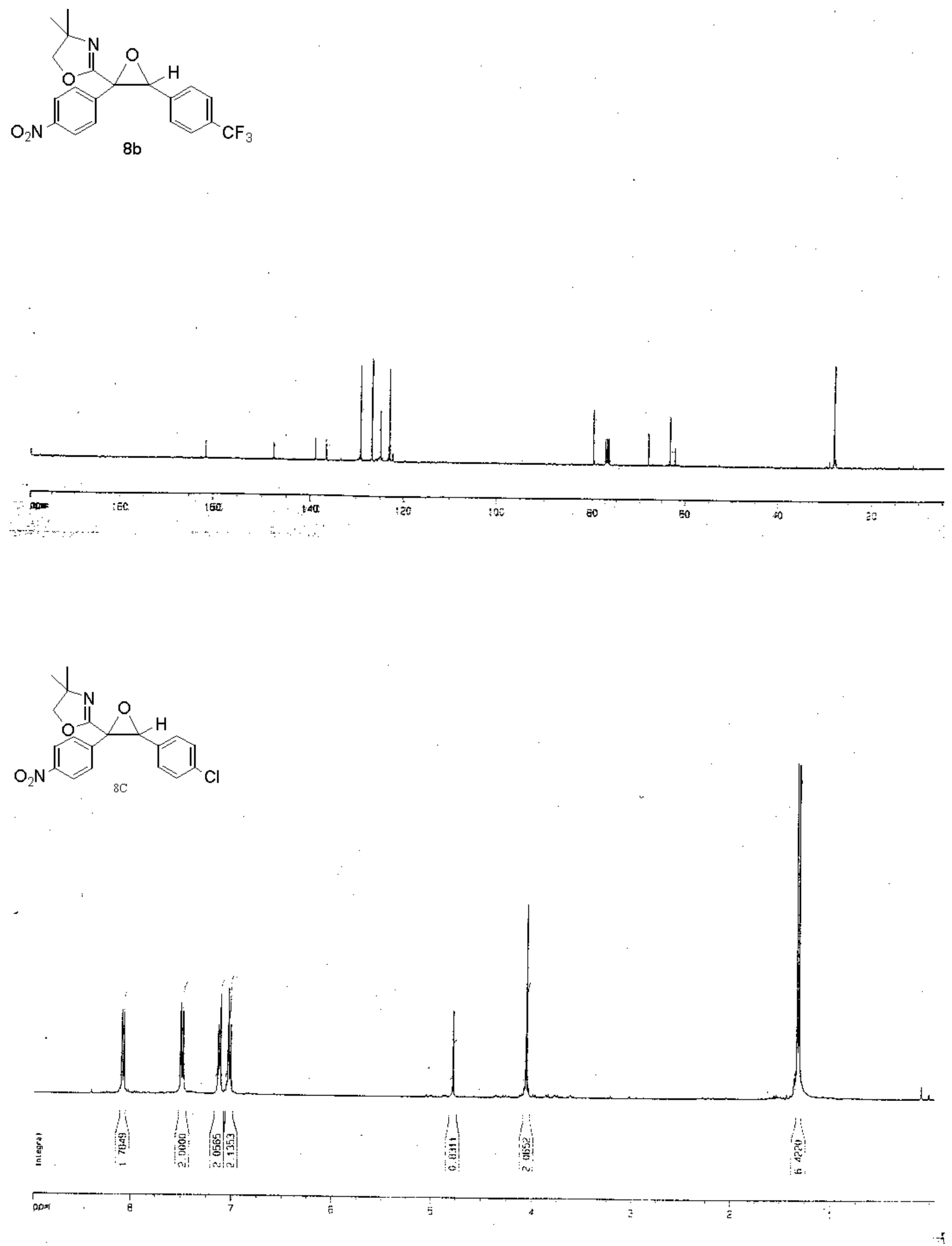

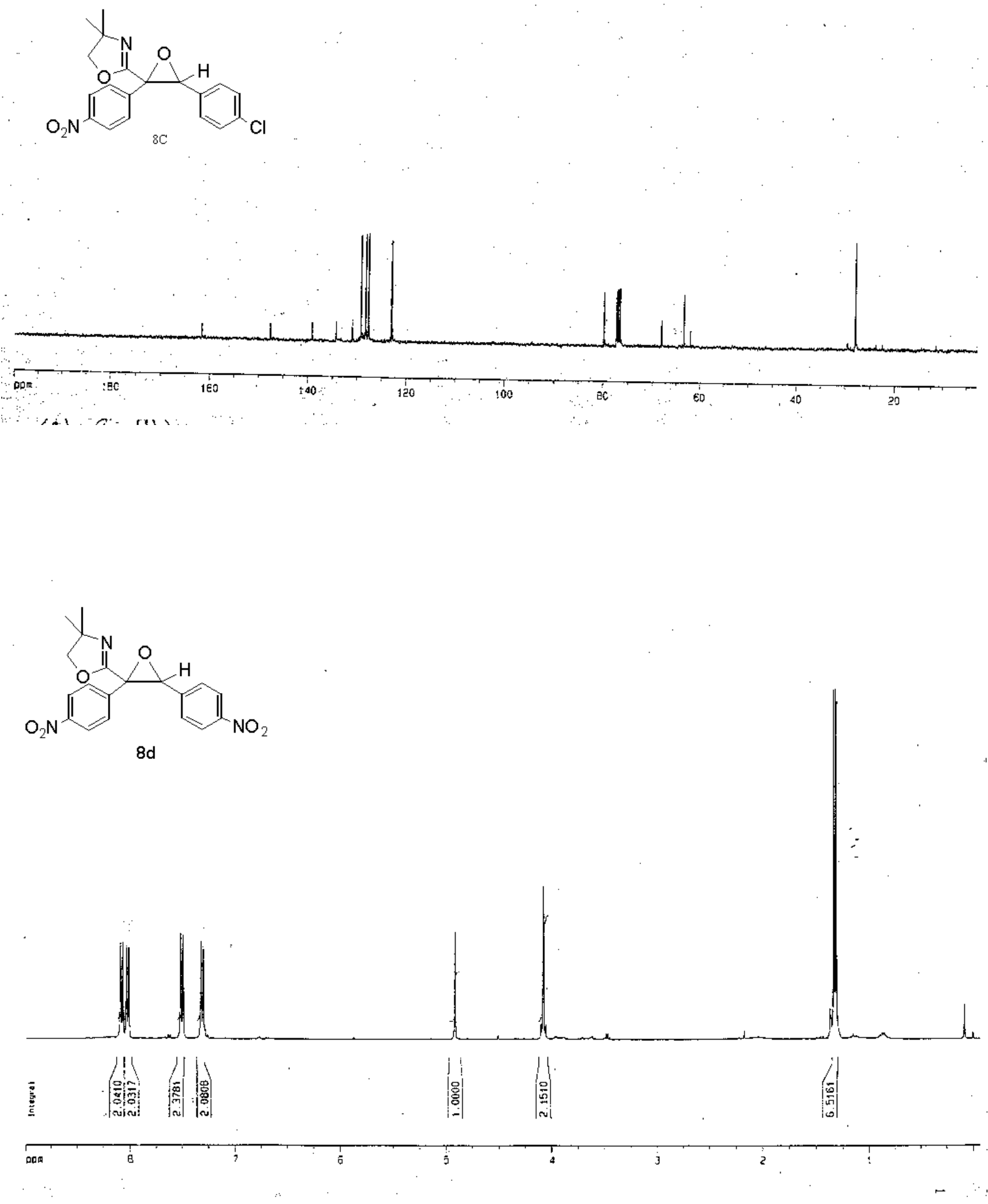

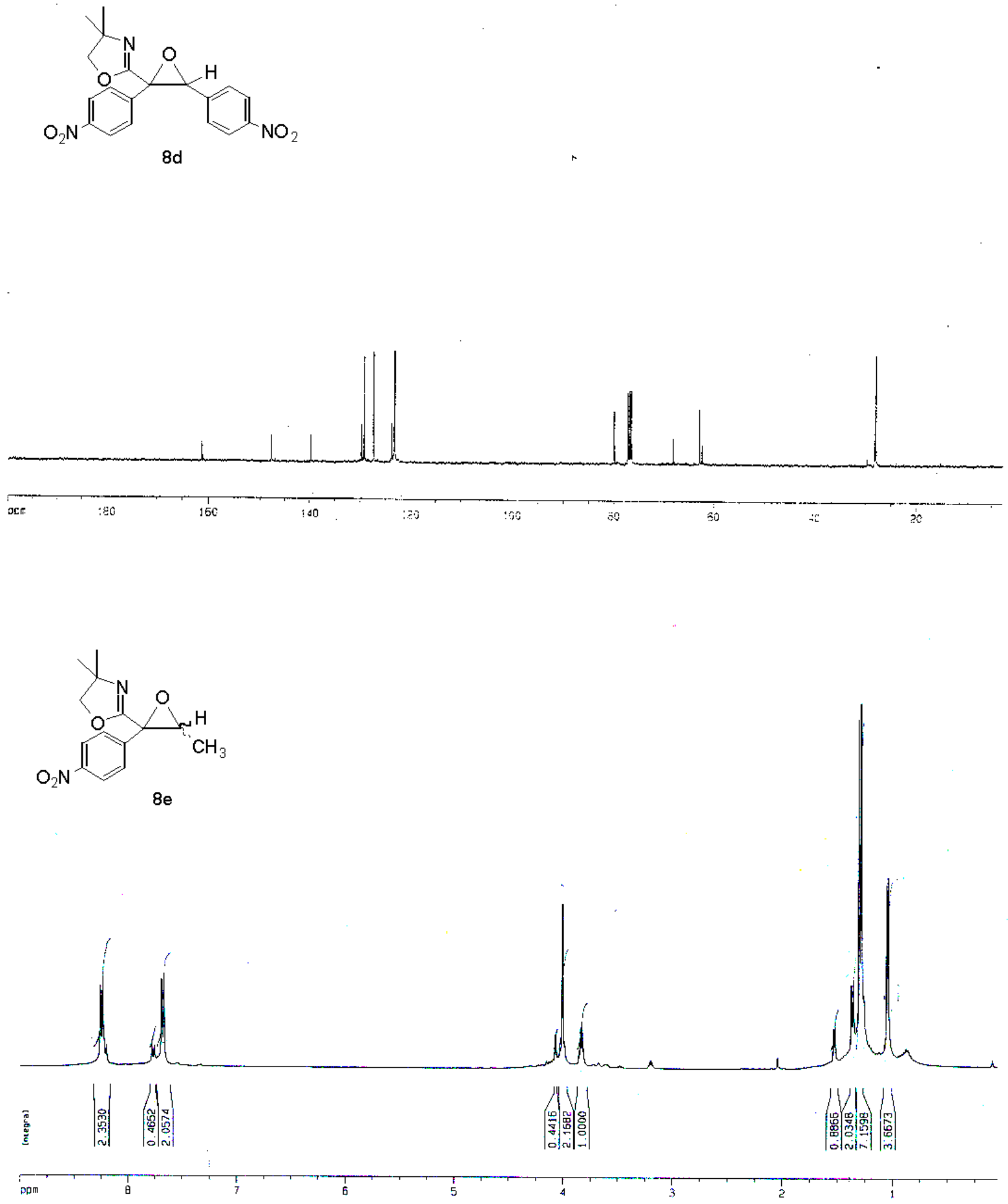

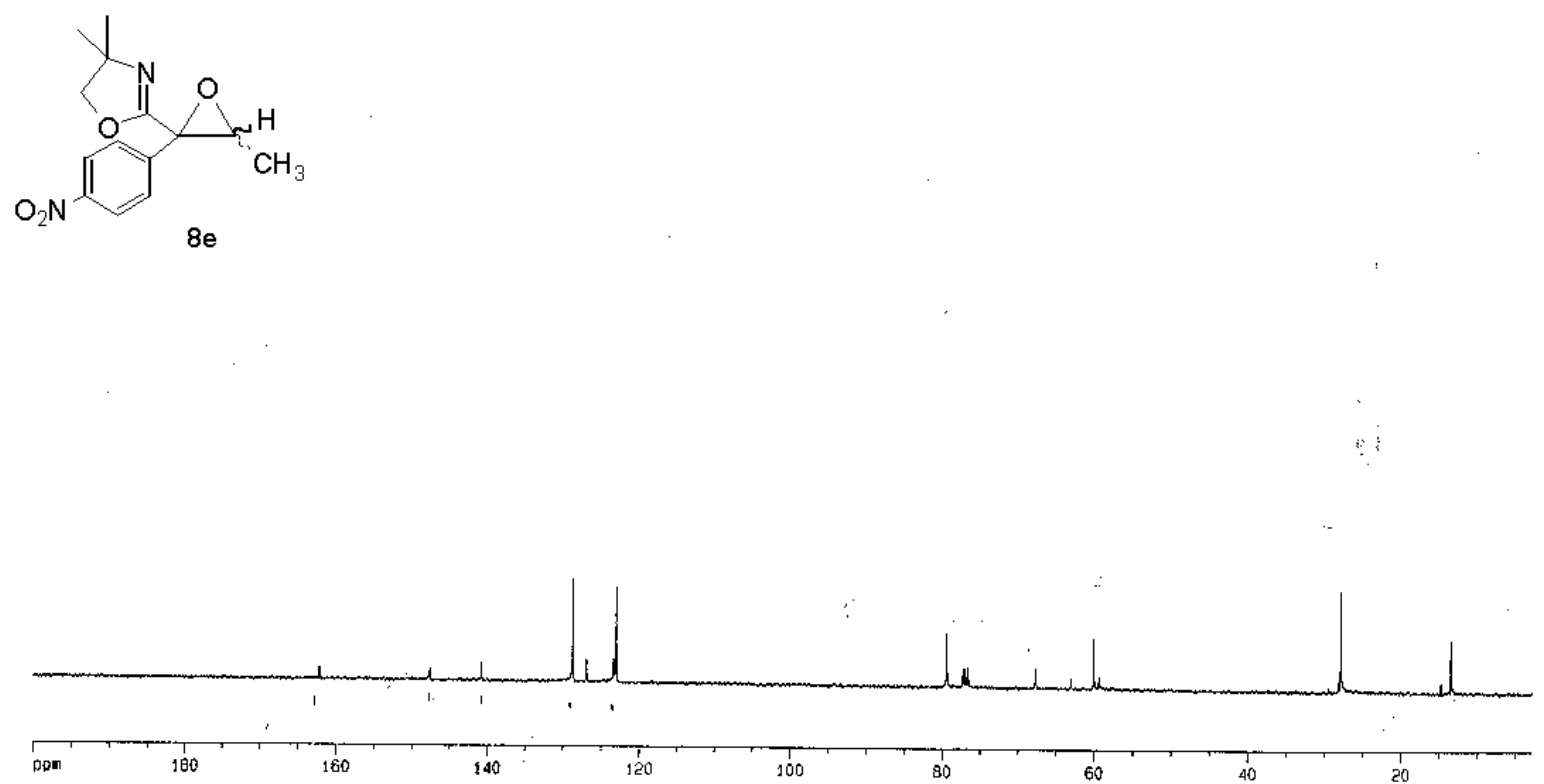

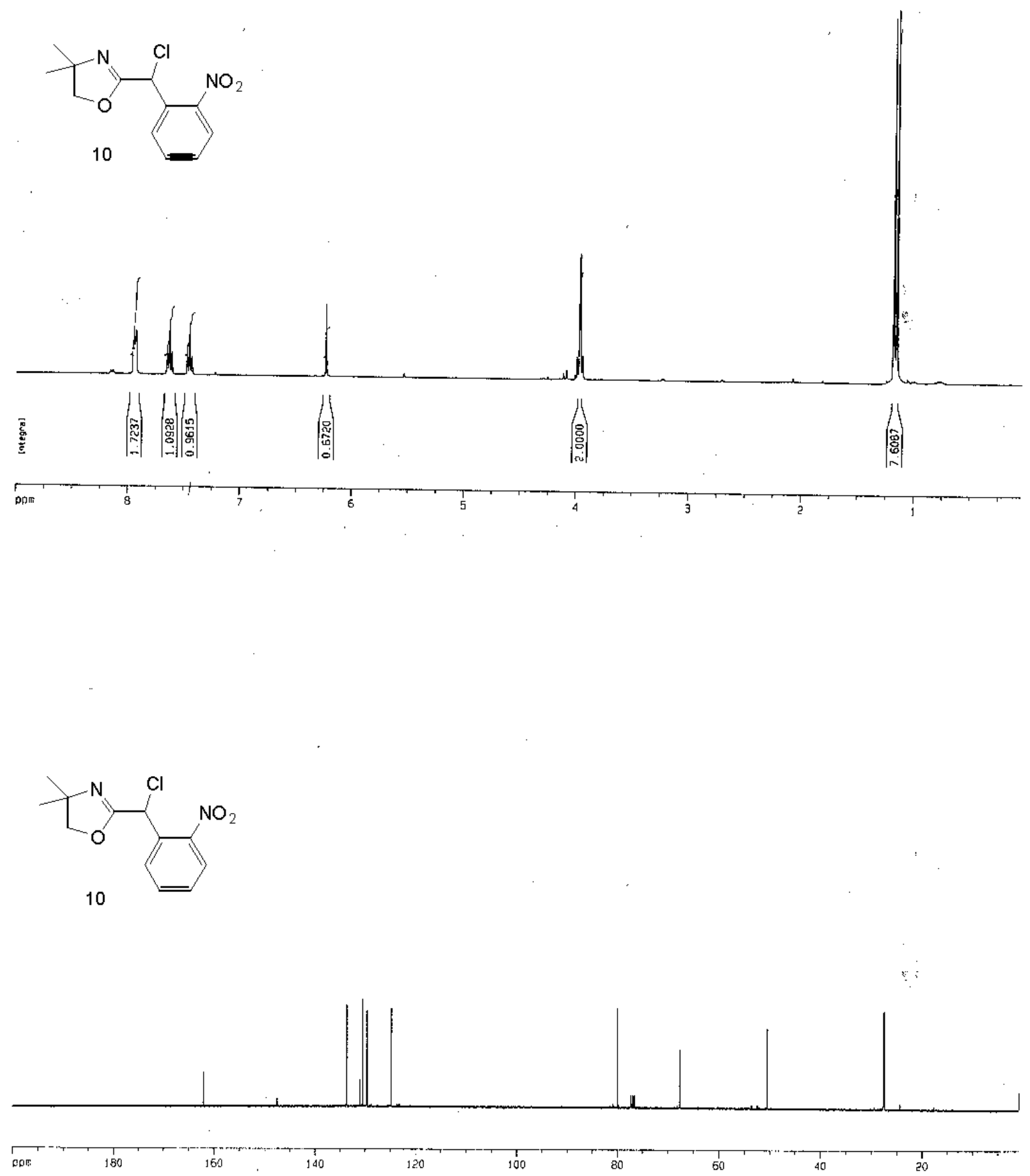

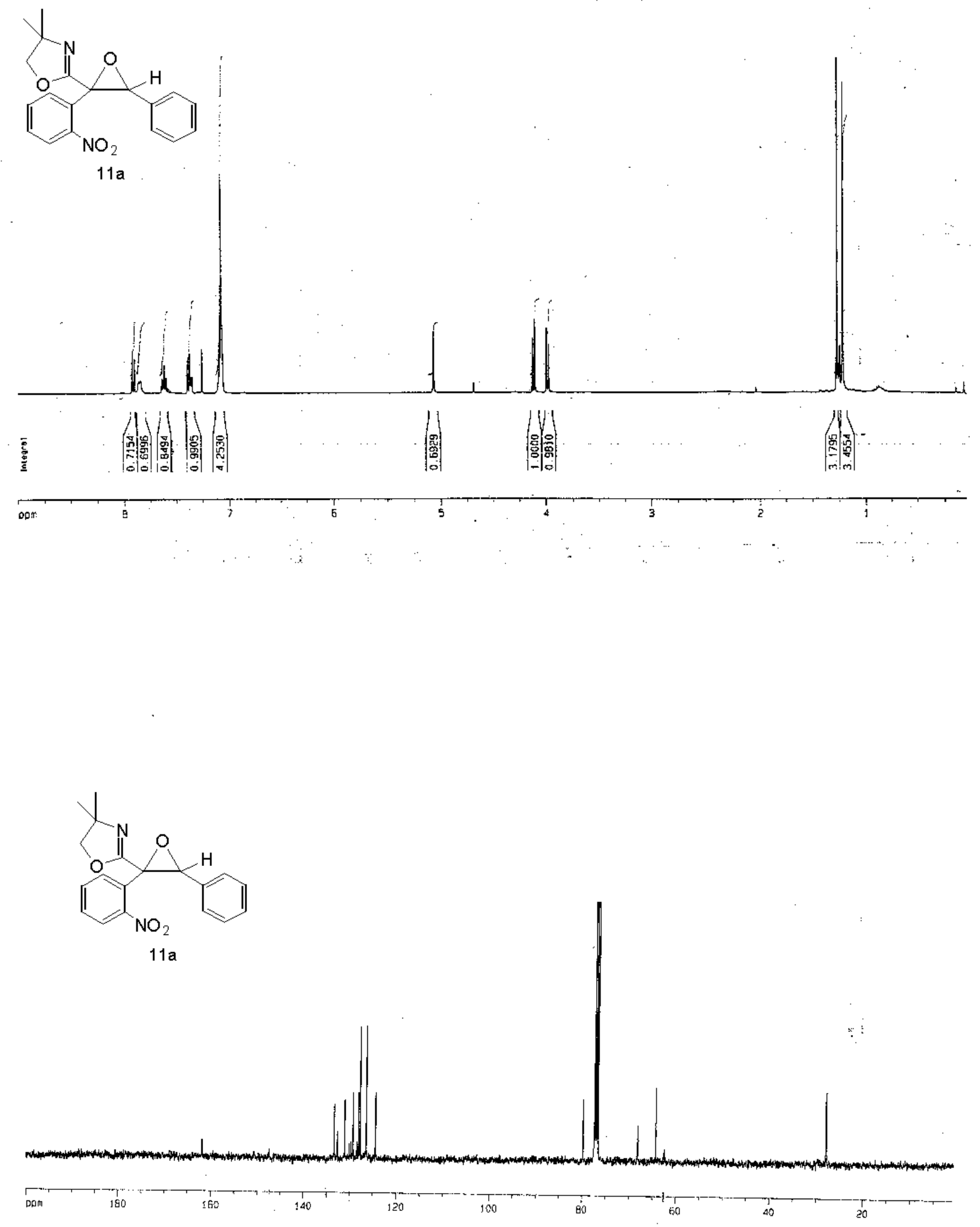

$11 \mathrm{a}$ 

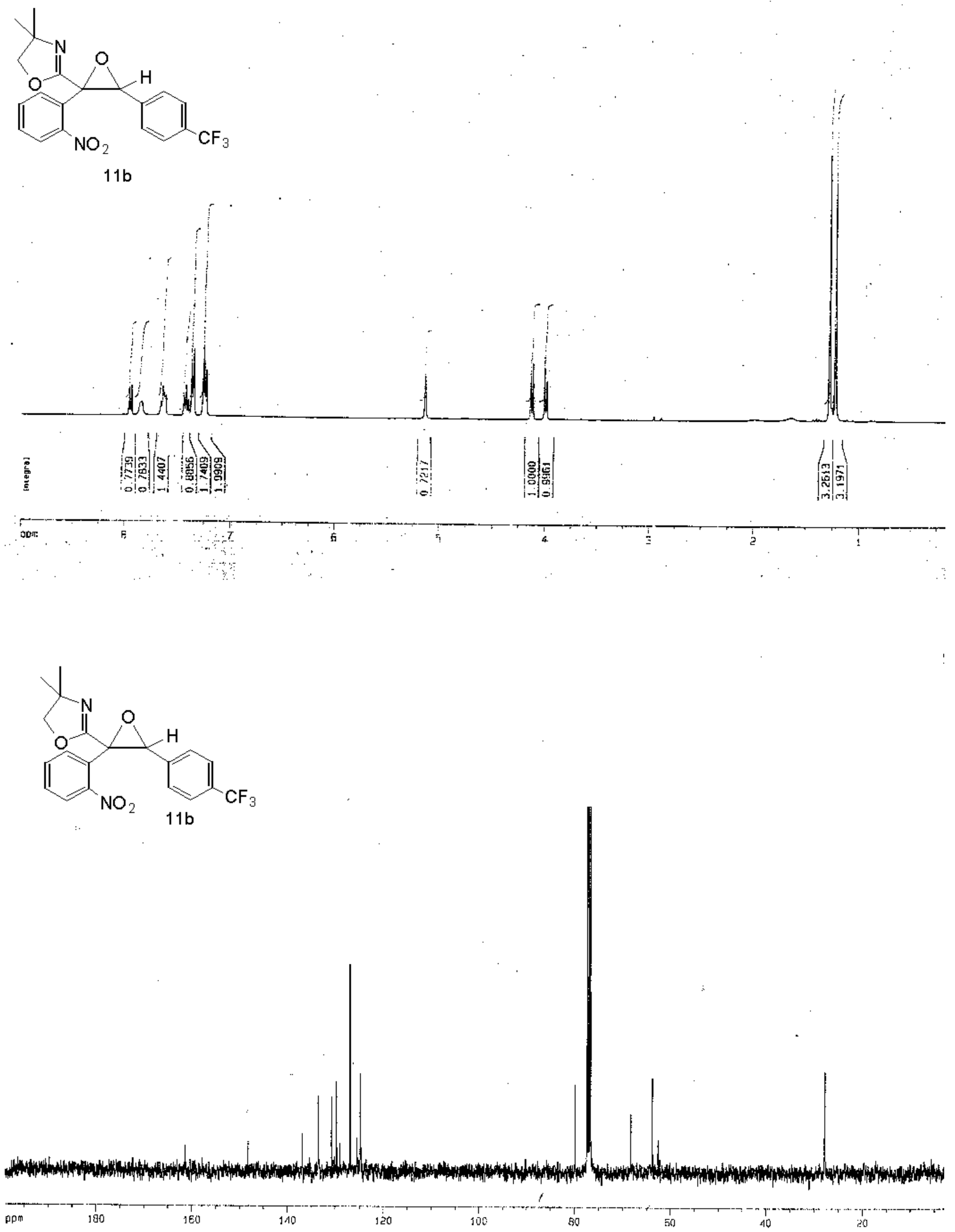

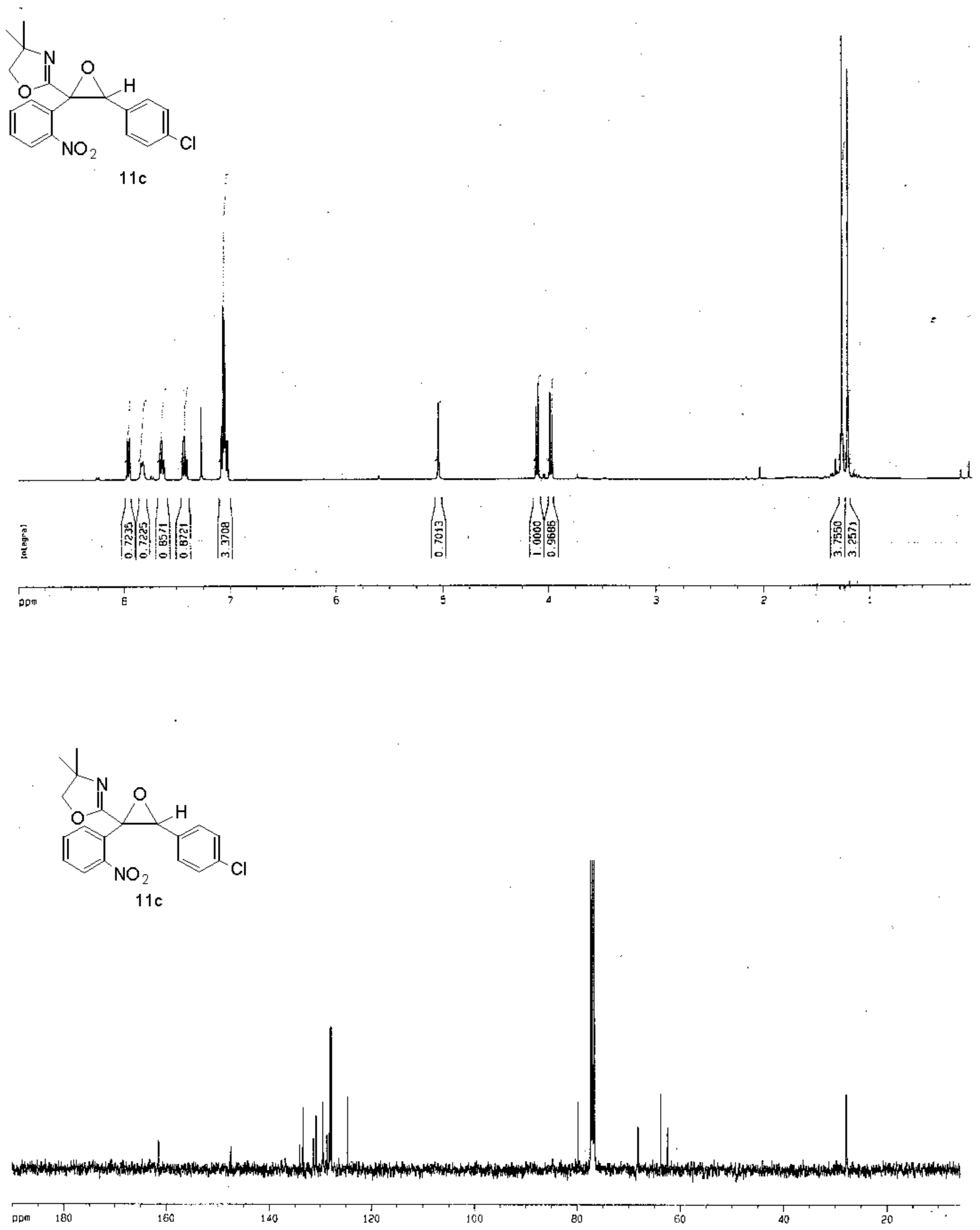

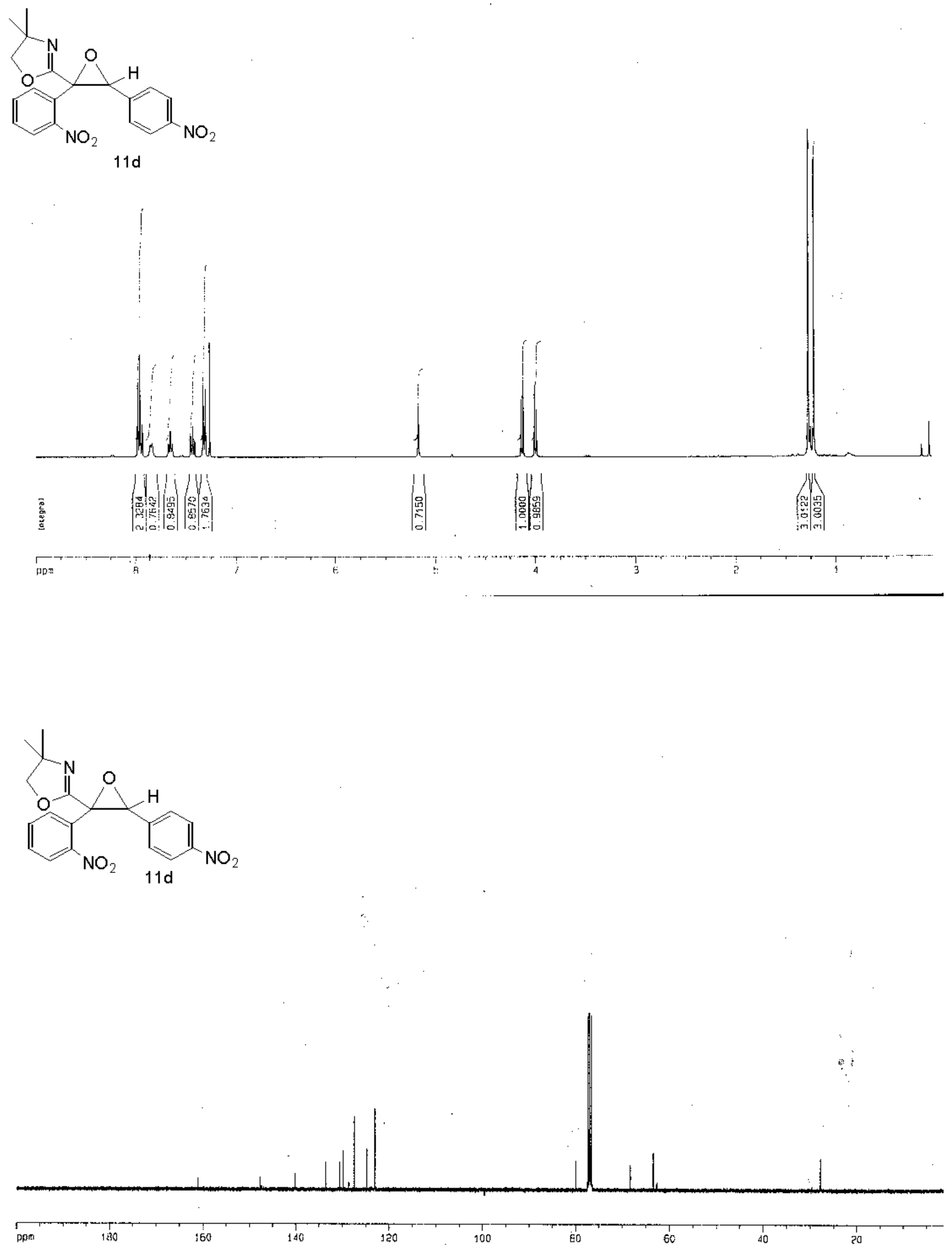


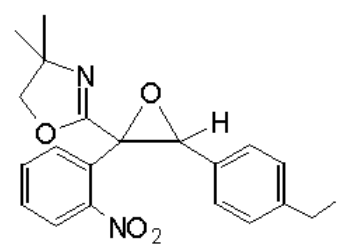

$11 \mathrm{e}$
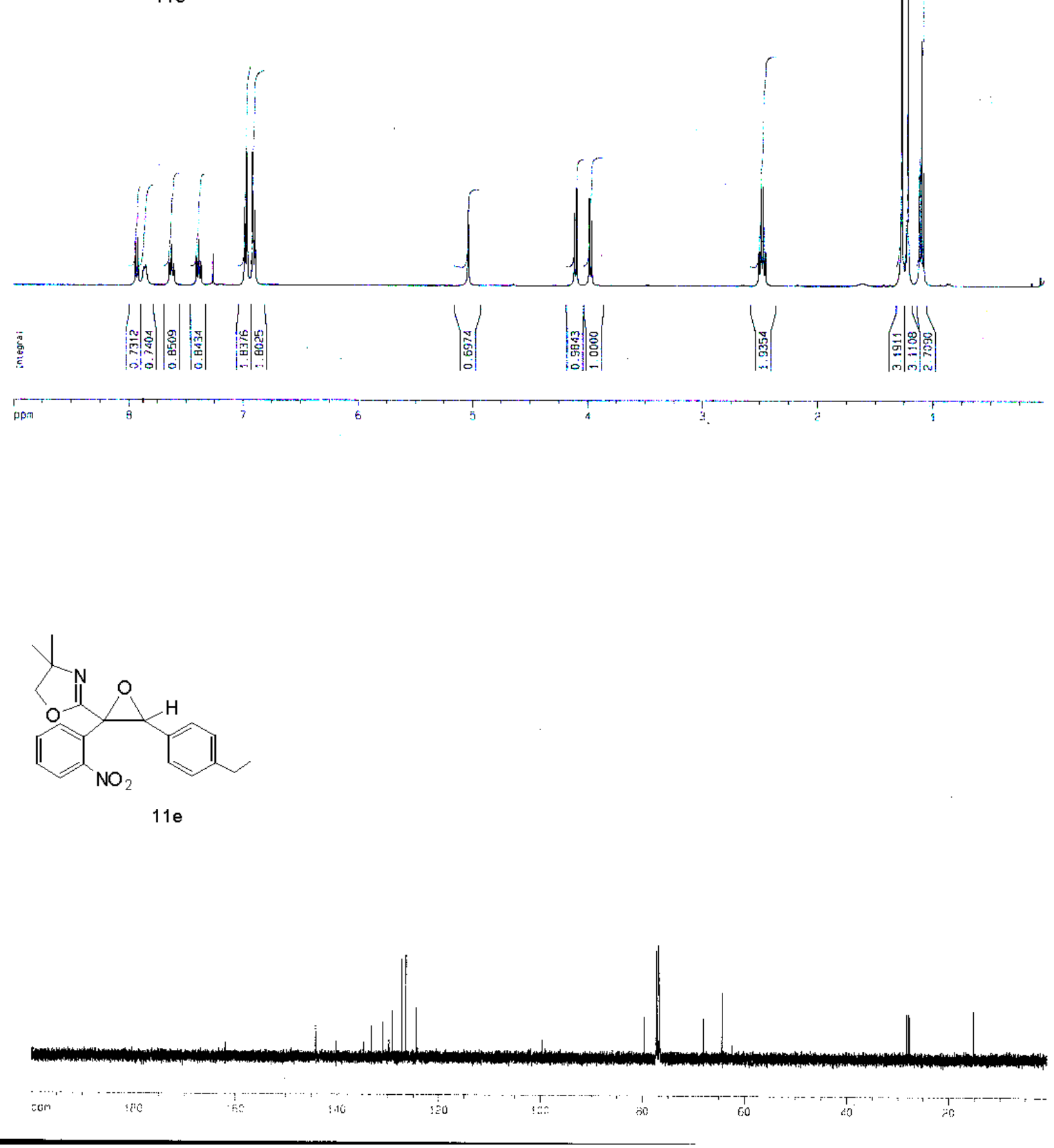

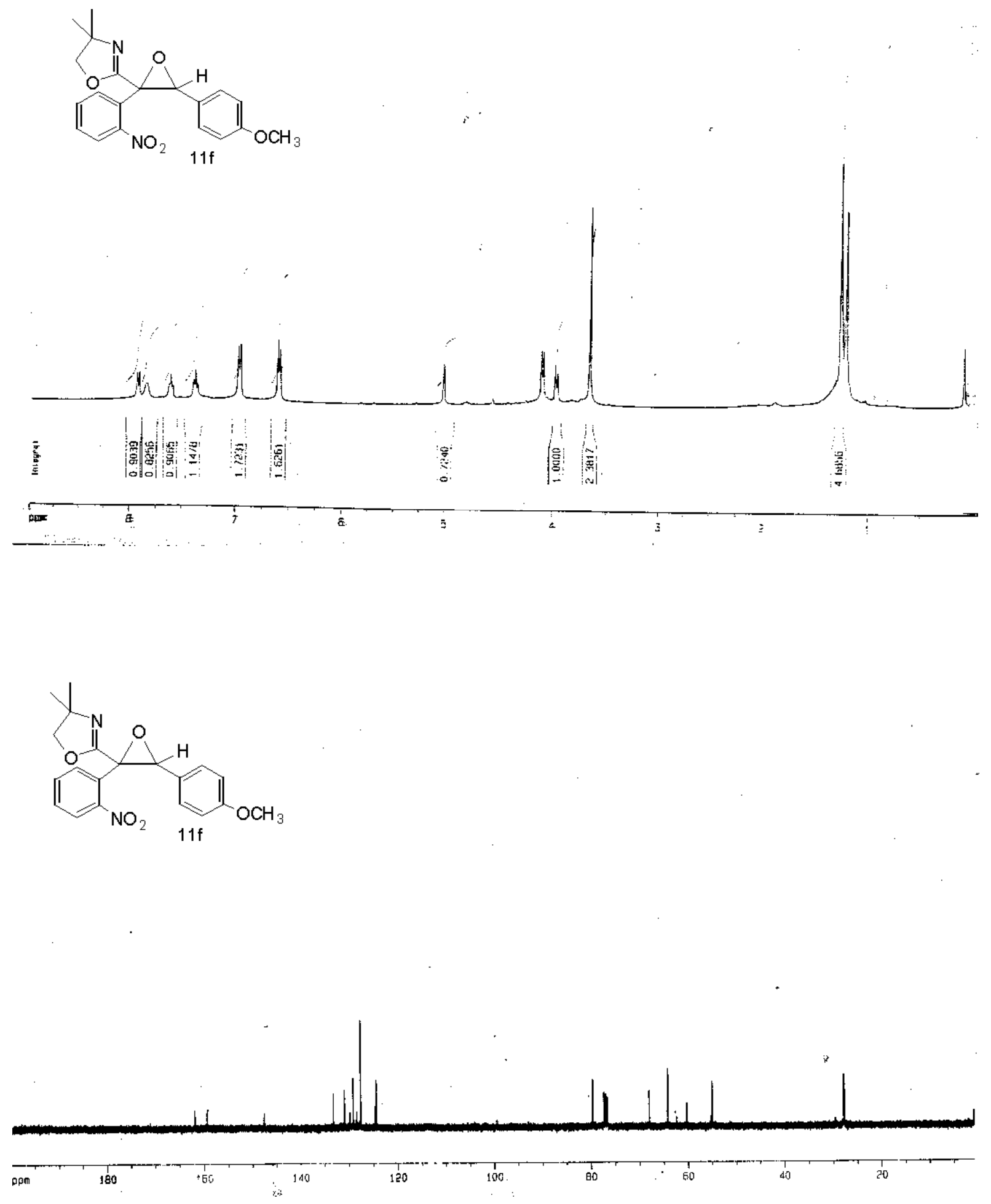


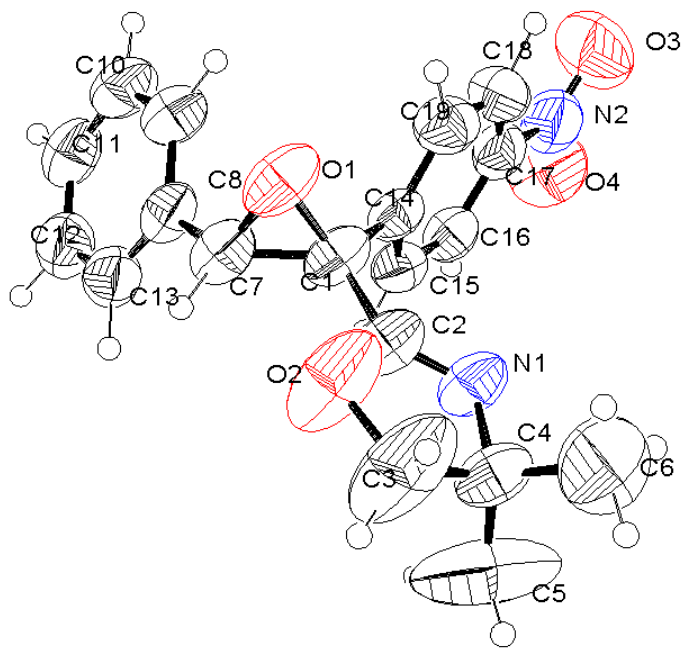

ORTEP view of oxazolinyloxirane $\mathbf{8 a}$

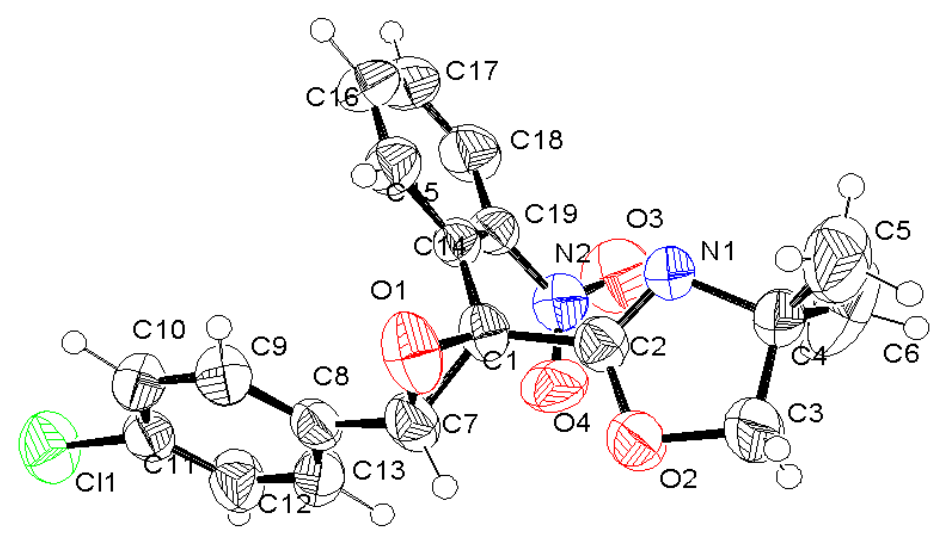

ORTEP view of oxazolinyloxirane 11c 